likely. It depends, of course, on what kind of library service is being provided. There were expenditure-per-student lows of $\$ 14.77$, $\$ 8.14, \$ 11.21$, and $\$ 12.96$ for the four groups of libraries in the CRL statistics. It is questionable if these institutions are well served by their libraries. In library service, as in most things, you get what you pay for, even though there may be occasional bargains.

Against the background of principles of college library service, Metcalf outlines a program for cooperative library service which would widen the scope of the Hampshire Inter-Library Center to include as associate members Dartmouth, Trinity (Hartford), Wesleyan, Williams, and the Forbes Library in Northampton. Associate members would provide entries for a partial union catalog, make materials listed in such a cata$\log$ available to faculty members and advanced students of the member and associatemember institutions, determine if materials are in the Center before applying elsewhere for interlibrary loans, and consult with the Center's catalog before new subscriptions are placed for highly specialized serials, before purchasing back files of serials, and before buying books of the kind listed in the catalog. Deliberate purchasing of materials would not be prevented, but the librarians would know when they would be duplicating. It is estimated that the partial union catalog would cost $\$ 12,000$. A possible budget for the Center for a year in the early 1960's would be $\$ 40,000$, not including income or expenditures made possible by grants, endowments, or the sale of duplicates.

Again, Metcalf out of his experience cautions against "dangers that call for continued vigilance." These involve those difficulties which "arise inevitably from the nature of libraries, academic institutions, and human beings." Cooperation is a two-way street, and the idea of competition must be submerged if it is to be furthered. Metcalf suggests that "administrative officials and librarians are perhaps more likely than professors to regard other institutions as rivals of their own and to be impatient with the restraints on complete freedom of action that are bound to be entailed by cooperation." This is an interesting hypothesis, since many librarians believe that professors are likely to be more concerned than anyone else. The important point is to make sure that the "human beings" involved in the cooperative project understand fully what is being planned, and how the individual institution will benefit by the project. Oiling and repairing are just as important here as in the care of any other machine.

The Hampshire Inter-Library Center in its six years of existence has been a demonstration of cooperation which suggests enlargement of scope. It would seem that some time in the future it may be useful to have a complete study of the use to which materials in the Center have been put. Undoubtedly, "the Center is making each dollar go further than it would go if spent by an individual library."-Maurice F. Tauber, Columbia University.

\section{Documentation and Information Retrieval}

Documentation and Information Retrieval:
An Introduction to Basic Principles and
Cost Analysis. By J. W. Perry and Allen
Kent. With a Foreword by J. H. Shera.
New York: Press of Western Reserve Uni-
versity and Interscience Publishers, Inc.,
1957. 156p. $\$ 5.00$.

A long-standing need for critical analysis of information retrieval in the present and potential states of the art is recognized in this monograph. The need is not fully met, but as a first attack the approach is praiseworthy.

A mathematical model system is set up, with formulations which are comprehensible to common minds. Indeed, the mathematical presentation is plainer than the verbal explanation, which uses too many words. Judicious verbal pruning would have improved clarity.

Cost analysis difficulties have long handicapped practitioners of information retrieval who preach the necessity of a cost-performance analysis before approving a system or project. The chapters on cost analysis in this monograph will give aid and comfort to these apostles of analysis. The critical faculty is exercised, as is necessary for such analyses, but not far enough. There is no adequate recognition of the intangible factors which 
act like mercury on glass when the analyst tries to put a finger on them.

The chapters on correlation of methods and on systems design do not bring out clearly enough the nature and magnitude of the gap now existing between systems design and machine design. Classification and coding systems have not yet caught up with existing machine potentialities; designers can say,. "Tell us how to program your requirements and we either have a machine to suit, or we can make one." This situation might be read between the lines, though the actual wording sometimes seems to suggest that machine design is behind rather than ahead of systems design. Again, greater clarity could have been achieved in fewer words.

The glossary of terms at the end is a useful feature. Exception can be taken to some of the definitions, but unanimous agreement in this area is rare. Dissenters are free to roll their own. The index of symbols is also useful.

Since the text says much about indexing, the index should be and is well done; the selection and arrangement of entries are commendable.-Julian F. Smith, LenoirRhyne College.

\section{Books West Southwest}

Books West Southwest, Essays on Writers, Their Books, and Their Land. By Lawrence Clark Powell. Los Angeles: Ward Ritchie Press (1957).

If Dr. Powell's library runs out of books one day he may always replenish it with books of his own composition. His latest collection contains twelve essays divided into three sections: Arizona and New Mexico (with a side glance at Texas), the California coast around Big Sur, and Los Angeles with its neighbors-the Land of the Future, may the Lord help us!

With exception of those devoted to Robinson Jeffers, the author's chief literary enthusiasm, and to Prof. J. F. Dobie, the essays deal with the Southwest and a selection of its literature. Dr. Powell has experienced powerful responses to the unique color of the Southwest, and he has nurtured and amplified them through much reading and writing. In these essays he again tries to repay the debt he owes to the land and the literature by setting out "to re-create in prose what makes this country so increasingly meaningful and necessary to one." His method is to seek what he calls essences, which he finds in "altitude, distance, color, configuration, history, and culture." To transmit these materials into evocative prose is his intent.

Dr. Powell's interest and reading have been long and wide, making his essays a pleasant introduction for those who have little or no experience with the states or the books he describes. Using a selective method (he disclaims any attempt at being exhaustive), he relates the effects which some twenty-five books, chiefly novels, have had on his understanding and emotional response to California and the Southwest. His choice is interesting and we owe him thanks for reminding us again of Willa Cather's beautiful Death Comes for the Archbishop and for reviving Haniel Long's profound Interlinear to Cabeza de Vaca.

The chapter on Jeffers portrays him as a major poet and a universal man. Particularly interesting is the claim that Jeffers had "Goethe's universal mind," some six years after graduation from college. Jeffers himself is quoted as writing that he "always rather disliked Goethe and his fame." A judgment is made that Jeffers is committed to classical models, Aristotelian and others, while at the same time he displays some kind of Christian morality by cleaving a thoroughfare through complex emotion to arrive at a "lysis," a settlement, and an adjusted balance. It seems to me the case is not convincing on the basis of the evidence presented.

The author uses a large number of foreign words and phrases, some of which are incorrect or inconsistent. For example, p. 106, reads todas instead of todos; accents are sometimes present on Spanish words, sometimes not; two species of oak are given Spanish names usually given to other species, and there are other puzzles, which may, however, be traced to careless proofreading, as may be also a number of wrong word divisions.

The book is nicely printed and pleasantly bound.-Joseph Rubinstein, University of Kansas. 